\title{
A survey on different challenges confronting auditing system
}

\author{
Hossein Mohammad Pour Zarandi ${ }^{\mathrm{a}}$, Mojgan Moharrami ${ }^{\mathrm{b}}$, Seyed Mohammad Sadegh Beheshti ${ }^{\mathrm{c}}$ and \\ Seyed Mohsen Tabatabaei Mozdabadi ${ }^{\mathrm{d}}$
}

\author{
${ }^{a}$ Postdoctoral of Economic Science, Tehran, Iran \\ ${ }^{b}$ University Professor, University of Applied Science and Technology, Tehran, Iran Tehran, Iran \\ ${ }^{c}$ University Professor, University of Applied Science and Technology, Tehran, Iran Tehran, Iran \\ ${ }^{d}$ Master of Educational Administration, lecturer of the university of Applied Science and Technology,, Tehran, Iran \\ C H R O N I C L E
}

Article history:

Received June 2, 2012

Received in revised format

28 October 2012

Accepted 30 October 2012

Available online

November 42012

Keywords:

Auditing system

Barriers

Municipality

\begin{abstract}
A B S T R A C T
Auditing plays an important role on having transparent financial statements especially in general organizations such as municipality, etc. A good implementation of auditing system helps reduce any possible fraud and increase the efficiencies of organizations. In this paper, we present an empirical survey to discuss barriers confronting auditing system. The proposed model designs and distributes a questionnaire between two groups of auditors and municipality managers. Cronbach alpha and KMO tests are used to verify the overall qualification of the survey and they are well above the minimum desirable level. The survey tests ten hypotheses including the effects of lack of standards and criteria, lack of experts, lack of awareness on advantages of auditing system, existence of conflicts in laws and regulation, etc. The results of t-test survey confirm all ten hypotheses and the implementation of Freedman test indicate that auditors have blamed using traditional methods as the most important barriers in using auditing techniques while managers believed lack of sufficient laws and regulations was the most important factors obstacle for using auditing system.
\end{abstract}

\section{Introduction}

Auditing plays an important role on having transparent financial statements especially in general organizations such as municipality, etc. A good implementation of auditing system helps reduce any possible fraud and increase the efficiencies of organizations (Quadackers et al., 1996). Therefore, it is important to detect important factors influencing risks and barriers associated with auditing systems (Bedard et al., 1999; Arens et al., 2005). Hajiha (2012) determined the critical influencing factors on risks proposed in Audit Risk Model (ARM), in Iranian audit environment of Iran. She used Delphi Method (Okoli \& Pawlowski, 2004; Turoff \& Linston, 2002), which consisted of 60 audit partners and managers. The panel consisted of two equally divided groups, the first one was from audit organization, a governmental organization, and the other one was from private audit firms. She used 
two times of Delphi and 58 critical risk factors extracted from auditing literature and Iranian auditing standards and presented them to some experts. There were 43 factors categorized as important factors to assess the risks associated with ARM. She reported that the most important factors, which includes inherent risk factors. She also made a comparison of her findings with a similar study in Taiwan and reported that in professional judgment issues like risk assessment, the consideration of specific culture and environment could help enhance the precision of assessments, especially in evaluating control risk factors. Bedard and Graham (2002) investigated the effects of decision help orientation on risk factor identification and audit test planning. Blay et al. (2008) performed an investigation on evidential effort and risk assessment in auditing. Chang et al. (2008) explained that the result of audit designation could be substantially impacted by the audit evidence collected when planning the audit and the amount of audit evidence depends on the degree of detection risk. Therefore, when the assessment factors of detection risk were more subjective and incorrect, audit costs and the risk of audit failure could be increased. To cope with this issue, Chang et al. (2008) designed an audit detection risk assessment system, which could more precisely evaluate risk detection risk, compared with the traditional techniques of risk detection to increase the audit quality and reduce the possibility of audit failure. They implemented grounded theory to reorganize 53 factors influencing detection risk mentioned in literatures and then used Delphi technique to screen the 43 critical risk factors agreed on by empirical audit experts. They also used fuzzy theory and audit risk model to measure the degree of detection risk, which permitted the audit staff to further detect the amount of audit evidence collected and set up initial audit strategies and built the audit detection risk assessment system.

Giroux et al. (2011) described changing patterns in the economic and institutional risk environment over time and studied differences based on empirical surrogates as measures of relative audit risk. They analyzed competitive, economic and regulatory differences, more specifically important events included the Foreign Corrupt Practices Act of 1977, the elimination of rules against advertising and direct solicitation in 1979 (increasing audit risk), the Private Securities Litigation Reform Act of 1995 (increasing risk), and the collapse of Arthur Andersen and Sarbanes-Oxley Act (2001-2002, reducing risk).

In this paper, we present an empirical survey to detect important factors influencing implementation of auditing system in Iran. The proposed study first presents problem statement in section 2, section 3 presents details of testing ten hypotheses of the survey and finally, concluding remarks are given in the last part to summarize the contribution of the paper.

\section{Problem statement}

The proposed study of this paper investigates different changes in implementing auditing system by designing a questionnaire, which includes three parts. In the first part, the objectives of the survey are explained while the second section gathers participants' general information such as age, gender, etc. Finally, the third part of the survey considers different hypotheses in terms of Likert based questions. The population of the survey includes all financial experts who reside in two provinces of Tehran and Alborz, Iran as well as managers who work for municipalities of two provinces of Ardebil and East Azarbaijan. The proposed study uses the following formula to calculate the minimum number of sample size,

$$
n=\frac{N \times z_{\alpha / 2}^{2} \times p \times q}{\varepsilon^{2} \times(N-1)+z_{\alpha / 2}^{2} \times p \times q},
$$

where $N$ is the population size, $p=1-q$ represents the yes/no categories, $z_{\alpha / 2}$ is CDF of normal distribution and finally $\varepsilon$ is the error term. Since we have $p=0.5, z_{\alpha / 2}=1.96$. There were two groups in our survey associated with auditing experts (195 people) and managers (191 people). Therefore, 
the sample sizes are calculated as 156 and 150, respectively. Cronbach alpha were calculated for ten questions in each group and the results are summarized in Table 1 as follows,

\section{Table 1}

The summary of Cronbach alpha and KMO tests

\begin{tabular}{llll}
\hline Row & Challenge & Cronbach & KMO \\
\hline 1 & Lack of standard and criteria & 0.86 & 0.83 \\
2 & Lack of expert employees & 0.75 & 0.95 \\
3 & Lack of familiarity of managers from the advantages of auditing system & 0.82 & 0.76 \\
4 & Conflicts among different laws and priorities & 0.85 & 0.91 \\
5 & Lack of expecting responsiveness & 0.74 & 0.75 \\
6 & Dependency on traditional methods & 0.85 & 0.86 \\
7 & Lack of necessary for being responsible to give appropriate reports & 0.93 & 0.90 \\
8 & Lack of intellectual independence & 0.81 & 0.73 \\
9 & Lack of sufficient laws and regulations & 0.78 & 0.80 \\
10 & Lack of effective and specialized organizations & 0.93 & 0.91 \\
\hline
\end{tabular}

As we can observe all Cronbach alphas are well above the minimum acceptable level, which validates the questionnaire. Next section, we present details of our testing various hypotheses.

\section{The results}

\subsection{First hypothesis: Lack of standard and criteria}

The first hypothesis of this survey is associated with lack of good standard and criteria as an important challenge for having auditing system.

$\mathrm{H}_{0}$ : The lack of good criteria and standards has no impact on applying auditing system.

$\mathrm{H}_{1}$ : The lack of good criteria and standards influences auditing system, significantly.

Chi-Square test has been calculated as 135.765 with four degree of freedom and P-value is equal to 0.000, which means we can reject the null hypothesis and conclude that lack of standards and good criteria influences implementation of auditing system when the level of significance is five percent.

The other test is to verify whether there is a meaningful difference between managers and auditing experts for the lack of standard and auditing system. Table 2 shows details of our survey.

\section{Table 2}

The results of statistical test for the different between two groups

\begin{tabular}{llllll}
\hline Lack of standard & Sum of squares & df & Mean of difference & F & Sig \\
\hline Between group & 62.916 & 3 & 20.972 & & \\
Inside group & 252.143 & 302 & 0.835 & 25.119 & 0.000 \\
\hline Total & 315.059 & 305 & & & \\
\hline
\end{tabular}

As we can observe from the results of Table 2, there is a meaningful difference between two groups in terms of shortage of standards and auditing systems when the level of significance is five percent.

\subsection{Second hypothesis: Lack of expert human resources}

The second hypothesis of this survey is associated with lack of skilled human resources as an important challenge for having auditing system. 
$\mathrm{H}_{0}$ : The lack of skilled human resources has no impact on applying auditing system.

$\mathrm{H}_{1}$ : The lack of skilled human resources influences auditing system, significantly.

Chi-Square test has been calculated as 162.235 with four degree of freedom and P-value is equal to 0.000, which means we can reject the null hypothesis and conclude that lack of skilled human resources influences implementation of auditing system when the level of significance is five percent.

The other test is to verify whether there is a meaningful difference between managers and auditing experts for the lack of skilled human resources. Table 3 shows details of our survey.

\section{Table 3}

The results of statistical test for the different between two groups

\begin{tabular}{llllll}
\hline Lack of standard & Sum of squares & df & Mean of difference & F & Sig \\
\hline Between group & 14.958 & 3 & 4.986 & & \\
Inside group & 200.571 & 302 & 0.664 & 7.507 & 0.000 \\
\hline Total & 215.529 & 305 & & & \\
\hline
\end{tabular}

As we can observe from the results of Table 3, there is a meaningful difference between two groups in terms of shortage of standards and auditing systems when the level of significance is five percent.

\subsection{Third hypothesis: Lack of familiarity with auditing system}

The third hypothesis of this survey is associated with lack of familiarity with auditing system as an important challenge for having auditing system.

$\mathrm{H}_{0}$ : The lack of familiarity with auditing system has no impact on applying auditing system.

$\mathrm{H}_{1}$ : The lack of familiarity with auditing system influences auditing system, significantly.

Chi-Square test has been calculated as 125.176 with four degree of freedom and P-value is equal to 0.000 , which means we can reject the null hypothesis and conclude that lack of familiarity with auditing system influences implementation of auditing system when the level of significance is five percent.

The other test is to verify whether there is a meaningful difference between managers and auditing experts for the lack of familiarity with auditing system. Table 4 shows details of our survey.

\section{Table 4}

The results of statistical test for the different between two groups

\begin{tabular}{llllll}
\hline Lack of standard & Sum of squares & df & Mean of difference & F & Sig \\
\hline Between group & 8.099 & 3 & 2.700 & & \\
Inside group & 312.371 & 302 & 1.034 & 2.610 & 0.052 \\
\hline Total & 320.471 & 305 & & & \\
\hline
\end{tabular}

As we can observe from the results of Table 4, there is no difference between two groups in terms of shortage of standards and auditing systems when the level of significance is five percent.

\subsection{Fourth hypothesis: Conflicts between laws and regulations}

The fourth hypothesis of this survey is associated with existing conflicts in laws and regulations as an important challenge for having auditing system. 
$\mathrm{H}_{0}$ : Existing conflicts in laws and regulations with auditing system has no impact on applying auditing system.

$\mathrm{H}_{1}$ : Existing conflicts in laws and regulations with auditing system influences auditing system, significantly.

Chi-Square test has been calculated as 232.235 with four degree of freedom and P-value is equal to 0.000 , which means we can reject the null hypothesis and conclude that existing conflicts in laws and regulations with auditing system influences implementation of auditing system when the level of significance is five percent.

The other test is to verify whether there is a meaningful difference between managers and auditing experts on existing conflicts in laws and regulations with auditing system. Table 5 shows details of our survey.

\section{Table 5}

The results of statistical test for the different between two groups

\begin{tabular}{llllll}
\hline Lack of standard & Sum of squares & df & Mean of difference & F & Sig \\
\hline Between group & 4.739 & 3 & 1.580 & & \\
Inside group & 257.143 & 302 & 0.851 & 1.855 & 0.137 \\
\hline Total & 261.882 & 305 & & & \\
\hline
\end{tabular}

As we can observe from the results of Table 5, there is no difference between two groups in terms of shortage of standards and auditing systems when the level of significance is five percent.

\subsection{Fifth hypothesis: Lack of being responsive}

The fifth hypothesis of this survey is associated with lack of being responsive as an important challenge for having auditing system.

$\mathrm{H}_{0}$ : Lack of being responsive for auditing system has no impact on applying auditing system.

$\mathrm{H}_{1}$ : Lack of being responsive influences auditing system, significantly.

Chi-Square test has been calculated as 190.471 with four degree of freedom and P-value is equal to 0.000, which means we can reject the null hypothesis and conclude that Lack of being responsive for auditing system for auditing system influences implementation of auditing system when the level of significance is five percent.

The other test is to verify whether there is a meaningful difference between managers and auditing experts on lack of being responsive for auditing system. Table 6 shows details of our survey.

\section{Table 6}

The results of statistical test for the different between two groups

\begin{tabular}{llllll}
\hline Lack of standard & Sum of squares & df & Mean of difference & F & Sig \\
\hline Between group & 5.875 & 3 & 1.958 & & \\
Inside group & 160.243 & 302 & 0.531 & 3.691 & 0.012 \\
\hline Total & 166.118 & 305 & & & \\
\hline
\end{tabular}

As we can observe from the results of Table 6, there is a difference between two groups in terms of lack of being responsive for auditing system when the level of significance is five percent.

\subsection{Sixth hypothesis: Traditional system}


The sixth hypothesis of this survey is associated with dependency on traditional system as an important challenge for having auditing system.

$\mathrm{H}_{0}$ : Using traditional system for auditing system has no impact on applying auditing system.

$\mathrm{H}_{1}$ : Using traditional system influences auditing system, significantly.

Chi-Square test has been calculated as 82.235 with four degree of freedom and P-value is equal to 0.03, which means we can reject the null hypothesis and conclude that using traditional system for auditing system influences implementation of auditing system when the level of significance is five percent.

The other test is to verify whether there is a meaningful difference between managers and auditing experts on lack of being responsive for auditing system. Table 7 shows details of our survey.

Table 7

The results of statistical test for the different between two groups

\begin{tabular}{llllll}
\hline Lack of standard & Sum of squares & df & Mean of difference & F & Sig \\
\hline Between group & 0.387 & 3 & 0.796 & & \\
Inside group & 216.671 & 302 & 0.717 & 1.109 & 0.346 \\
\hline Total & 219.059 & 305 & & & \\
\hline
\end{tabular}

As we can observe from the results of Table 7, there is no difference between two groups in terms of using traditional system for auditing system when the level of significance is five percent. In other words, both groups agree that using traditional system plays an important role on preventing implementation of auditing system.

\subsection{Seventh hypothesis: Lack of necessity}

The seventh hypothesis of this survey is associated with lack of necessity for having auditing system as an important challenge for having auditing system.

$\mathrm{H}_{0}$ : Lack of necessity for having auditing system has no impact on applying auditing system.

$\mathrm{H}_{1}$ : Lack of necessity for having auditing system influences auditing system, significantly.

Chi-Square test has been calculated as 277.2 with four degree of freedom and P-value is equal to 0.000, which means we can reject the null hypothesis and conclude that lack of necessity for having auditing system influences implementation of auditing system when the level of significance is five percent.

The other test is to verify whether there is a meaningful difference between managers and auditing experts on lack of being responsive for auditing system. Table 8 shows details of our survey.

Table 8

The results of statistical test for the different between two groups

\begin{tabular}{llllll}
\hline Lack of standard & Sum of squares & df & Mean of difference & F & Sig \\
\hline Between group & 2.347 & 3 & 0.791 & & \\
Inside group & 321.746 & 296 & 1.087 & 0.728 & 0.536 \\
\hline Total & 324.120 & 299 & & & \\
\hline
\end{tabular}

As we can observe from the results of Table 8, there is no difference between two groups in terms of using traditional system for auditing system when the level of significance is five percent. In other words, both groups agree that lack of necessity for having auditing system plays an important role on preventing implementation of auditing system. 


\subsection{Eighth hypothesis: Lack of intellectual independence}

The eighth hypothesis of this survey is associated with lack of having intellectual independence for having auditing system as an important challenge for having auditing system.

$\mathrm{H}_{0}$ : Lack of intellectual independence for having auditing system has no impact on applying auditing system.

$\mathrm{H}_{1}$ : Lack of intellectual independence for having auditing system influences auditing system, significantly.

Chi-Square test has been calculated as 109.882 with four degree of freedom and P-value is equal to 0.01, which means we can reject the null hypothesis and conclude that lack of necessity for having auditing system influences implementation of auditing system when the level of significance is five percent.

The other test is to verify whether there is a meaningful difference between managers and auditing experts on lack of being responsive for auditing system. Table 9 shows details of our survey.

\section{Table 9}

The results of statistical test for the different between two groups

\begin{tabular}{llllll}
\hline Lack of standard & Sum of squares & df & Mean of difference & F & Sig \\
\hline Between group & 28.632 & 3 & 9.544 & & \\
Inside group & 305.286 & 296 & 1.012 & 9.435 & 0.000 \\
\hline Total & 334.118 & 299 & & & \\
\hline
\end{tabular}

As we can observe from the results of Table 9, there is a difference between two groups in terms of using traditional system for auditing system when the level of significance is five percent. In other words, both groups disagree on this item and may think differently in terms of personality of people.

\subsection{Ninth hypothesis: Lack of sufficient laws and regulations}

The ninth hypothesis of this survey is associated with lack of sufficient laws and regulations for having auditing system as an important challenge for having auditing system.

$\mathrm{H}_{0}$ : Lack of sufficient laws and regulations for having auditing system has no impact on applying auditing system.

$\mathrm{H}_{1}$ : lack of sufficient laws and regulations for having auditing system influences auditing system, significantly.

Chi-Square test has been calculated as 61.529 with four degree of freedom and P-value is equal to 0.017, which means we can reject the null hypothesis and conclude that lack of necessity for having auditing system influences implementation of auditing system when the level of significance is five percent. The other test is to verify whether there is a meaningful difference between managers and auditing experts on lack of being responsive for auditing system. Table 10 shows details of our survey.

Table 10

The results of statistical test for the different between two groups

\begin{tabular}{llllll}
\hline Lack of standard & Sum of squares & df & Mean of difference & F & Sig \\
\hline Between group & 37.785 & 3 & 12.595 & & \\
Inside group & 210.686 & 296 & 0.698 & 18.054 & 0.000 \\
\hline Total & 248.471 & 299 & & & \\
\hline
\end{tabular}


As we can observe from the results of Table 10, there is a difference between two groups in terms of using traditional system for auditing system when the level of significance is five percent.

\subsection{Tenth hypothesis: Lack of good associations}

The last hypothesis of this survey is associated with lack of good associations for having auditing system as an important challenge for having auditing system.

$\mathrm{H}_{0}$ : Lack of good associations for having auditing system has no impact on applying auditing system. $\mathrm{H}_{1}$ : Lack of good associations for having auditing system influences auditing system, significantly.

Chi-Square test has been calculated as 147.529 with four degree of freedom and P-value is equal to 0.000 , which means we can reject the null hypothesis and conclude that lack of good association for having auditing system influences implementation of auditing system when the level of significance is five percent.

The other test is to verify whether there is a meaningful difference between managers and auditing experts on lack of being responsive for auditing system. Table 11 shows details of our survey.

Table 11

The results of statistical test for the different between two groups

\begin{tabular}{llllll}
\hline Lack of standard & Sum of squares & df & Mean of difference & F & Sig \\
\hline Between group & 14.164 & 3 & 4.721 & & \\
Inside group & 274.071 & 296 & 0.908 & 5.202 & 0.002 \\
\hline Total & 288.235 & 299 & & & \\
\hline
\end{tabular}

As we can observe from the results of Table 11, there is a difference between two groups in terms of using traditional system for auditing system when the level of significance is five percent. An establishment of a powerful auditing organization can help prepare educational training programs as well as improving quality of auditing programs through standardization policy making.

Finally, we have measured the relative importance of ten factors based on Freeman test and Table 12 summarizes the results of our survey.

\section{Table 12}

The summary of Freedman test for two groups of auditors and managers

\begin{tabular}{llll}
\hline Row & Challenge & Auditors & Managers \\
\hline 1 & Lack of standard and criteria & 7.63 & 4.92 \\
2 & Lack of expert employees & 5.53 & 5.19 \\
3 & Lack of familiarity of managers from the advantages of auditing system & 5.20 & 7.35 \\
4 & Conflicts among different laws and priorities & 6.23 & 6.96 \\
5 & Lack of expecting responsiveness & 5.77 & 6.77 \\
6 & Dependency on traditional methods & 9.77 & 6.38 \\
7 & Lack of necessary for being responsible to give appropriate reports & 4.90 & 6.58 \\
8 & Intellectual independence & 4.43 & 8.15 \\
9 & Lack of sufficient laws and regulations & 6.53 & 8.46 \\
10 & Lack of effective and specialized organizations & 5.90 & 7.23 \\
\hline
\end{tabular}

As we can observe from the results of Table 12, auditors have blamed using traditional methods as the most important barriers in using auditing techniques while managers believed lack of sufficient laws and regulations were the most important factors obstacle for using auditing system. In addition, managers blamed intellectual independence, 


\section{Conclusion}

In this paper, we have presented an empirical study to measure the effects of different factors preventing us to use auditing systems. The proposed study of this paper has detected ten factors including lack of standard and criteria, lack of expert employees, lack of familiarity of managers from the advantages of auditing system, conflicts among different laws and priorities, lack of expecting responsiveness, dependency on traditional methods, lack of necessary for being responsible to give appropriate reports, intellectual independence, lack of sufficient laws and regulations and lack of effective and specialized organizations as the most important factors influencing the implementation of auditing system. In addition, while auditors have blamed using traditional methods as the most important barriers in using auditing techniques, managers believed lack of sufficient laws and regulations were the most important factors obstacle for using auditing system. Among the other important factors in auditors' perspective, we can specify conflicts among different laws and priorities and lack of sufficient laws and regulations while the auditors believed lack of familiarity of managers from the advantages of auditing system was the most important factor influencing auditing implementation. Therefore, we can suggest governmental organization to look for transparent legislation to help people have better access in auditing system. In other words, it is quite possible to remove many contradicting rules and regulations to help different industries use such systems.

\section{Acknowledgment}

The authors would like to thank the officials of municipality organizations for cordially helping the accomplishment of this survey. We are also grateful for the insight received from expert auditors who participated in our survey.

\section{References}

Arens, A.A., Elder, R. J., \& Beaslsy, M. S. (2005). Auditing and Assurance Services: An Integrated Approach. $10^{\text {th }}$ ed., Upper Saddle River, New Jersey: Prentice Hall.

Audit Organization: Iranian Audit Procedure Revision Committee (2000). Revised sections with an audit risk management approach. Tehran, Iran.

Bedard, J., Mock, T., \& Wright, A. (1999). Evidential Planning in Auditing: A Review of the Empirical Research. Journal of Accounting Literature, 18, 96-142.

Bedard, J.C., \& Graham, L.E. (2002). The effects of decision aid orientation on risk factor identification and audit test planning. Auditing: A Journal of Practice and Theory, 21(2), 39-56.

Blay, A., Kizirian, T., \& Dwight, S. (2008). Evidential effort and risk assessment in auditing. Journal of Business \& Economics Research, 6, 39-59.

Chang, S.I., Tsai, C.F. \& Shih, D. H. (2007).The development of audit detection risk assessment system: using the fuzzy theory and audit risk model. Experts System Application, 35(3), 10531067.

Cronbach, L. J. (1951). Coefficient alpha and the internal structure of tests. Psychometrika, 16(3), 297-334.

Giroux, G., \& Cassell, C. (2011). Changing audit risk characteristics in the public client market. Research in Accounting Regulation, 23(2), 177-183

Hajiha, Z. (2012). Application of Delphi method for determining the affecting factors upon audit risk model. Management Science Letters, 2(1), 379-390.

Likert, R. (1932). A Technique for the Measurement of Attitudes. Archives of Psychology, 140, 1-55.

Okoli, C., \& Pawlowski, S.D. (2004). The Delphi method as a research tool: an example, design considerations and applications. Information and Management, 42(1), 15-29.

Quadackers, L., Mock, T., \& Maijoor, S. (1996). Audit risk and audit programs: Archival evidence from four Dutch audit firms. European Accounting Review, 5(2), 217-237. 
Turoff, M., \& Linston, H.A. (2002). The Delphi Method: Techniques and Applications. Addison Wesley. 